This document is the Accepted Manuscript version of a Published Work that appeared in final form in "2D Materials" after peer review and technical editing by the publisher. To access the final edited and published work see: https://doi.org/10.1088/2053-1583/4/1/015020

\title{
Managing heat phenomena in epoxy composites production via graphenic derivatives: synthesis, properties and industrial production simulation of Graphene and Graphene Oxide containing composites
}

\footnotetext{
Laura Mazzocchetti ${ }^{1,2}$, Emanuele D'Angelo ${ }^{1}$, Tiziana Benelli ${ }^{1,2}$, Simone Ligi ${ }^{3}$, Giangiacomo Minak ${ }^{2,4}$, Emanuel Poodts ${ }^{5}$, Vincenzo Palermo ${ }^{6}$, Fabrizio Tarterini ${ }^{2,4}$, Loris Giorgini ${ }^{1,2}$

${ }^{1}$ Dipartimento di Chimica Industriale “Toso Montanari”, University of Bologna, Viale Risorgimento 4, 40136 Bologna, Italy

${ }^{2}$ Interdepartmental Center for Industrial Research on Advanced Applications in Mechanical Engineering and Materials Technology, CIRI-MAM, University of Bologna, Viale Risorgimento 2, 40136 Bologna, Italy

${ }^{3}$ GNext sas Via d'Azeglio, 40123 Bologna, Italy

${ }^{4}$ Industrial Engineering Dept., University of Bologna, Viale Risorgimento 2, 40136 Bologna, Italy

${ }^{5}$ Kohlenia srl, 1618, Carlos Tejedor 2576, B1610CXF Ricardo Rojas, Buenos Aires,
} Argentina

${ }^{6}$ Istituto per la Sintesi Organica e la Fotoreattività-Consiglio Nazionale delle Ricerche (ISOFCNR), via Gobetti 101, 40129 Bologna, Italy 


\begin{abstract}
A commercial two-components epoxy resin formulation was successfully modified by adding graphene and related materials (GRMs) and the effect of these nanofillers was assessed on their thermomechanical properties as well as on the simulation of their industrial application for the production of thick composites objects with interesting results. GMRs were added in different concentrations in order to improve thermomechanical properties of the nano-composite thermoset. Different dispersion methods were taken into account in order to produce stable long-lasting dispersion of the GRMs, that can withstand a commercial shelf life. Addition of the GRMs improves the glass transition temperature of the nanocomposite up to $20^{\circ} \mathrm{C}$ with respect to the plain commercial formulation, and both stress and elongation at break increase up to almost 4 times the original values. Moreover, the industrial curing of some of the more promising modified resins was computer-simulated when the two-components resins are used to produce a carbonfiber reinforced thick composite beam. Simulation results show that some of the applied GRMs helps reducing or even completely preventing the overheat phenomena that are well renown to induce significant thermal stresses negatively affecting the final object performances. These interesting effects would contribute reducing the time required for a single industrial production cycle, since no time for overheat dispersion is required, thus helping increasing the production rate.
\end{abstract}

Keywords: Graphene; Graphene Oxide; Carbon Fiber Reinforced Composites; Curing Simulation; Epoxy Resin. 


\section{Introduction}

Carbon Fibre Reinforced Composites (CFRCs) are presently used for a number of advanced applications. Though CFRCs are still considered a market niche, their applications both as aesthetic and as structural materials are growing faster and faster thanks to their particularly captivating aspect and their high strength to weight and stiffness to weight ratios which are able to provide final objects with light weight and outstanding mechanical properties. Up to now CFRCs are mainly produced as thin materials, where the most outstanding properties can be reached in the direction of the fibre axis while the orthogonal directions, where the resin properties play the major role, are usually characterized by poor mechanical properties. While, indeed, the matrix plays a minor role in the tensile load-carrying capacity of a CFRC, it has a major influence on the compressive, inter laminar shear as well as in-plan and shear properties of the final composite material. The thermo-mechanical performance of the matrix fraction is particularly demanding when the number of stacking layers of aligned fibres increases: Thick Carbon Fibre Reinforced Composites (TCFRCs) might lead to superior mechanical properties and very lightweight objects, compared to traditional materials. The TCFRC production is however quite challenging [1-3], with possible strong overheating phenomena that might degrade the polymeric component [4-6] and trigger critical failure events at the layers interface or, more generally speaking, at the fibre/matrix interface and in the resin "bulk". Despite increasing the fibre/matrix adhesion with improved fibre sizing might help solve some of the issues, in the end the intrinsic properties of the matrix remain the limiting factor in the thermomechanical performance of the composite. Hence, the enhancement of the matrix overall performances may be of further value.

In this frame, graphene was shown in the literature to dramatically boost the mechanical performances of different kinds of polymers [7], often providing some additional interesting functional features [8-10]. Small weight fractions of graphenic derivatives are reported to increase properties by at least an order of magnitude, without actually affecting the chemistry of the polymer itself [11]. The GRMs delivery within the polymer matrix can be carried out directly or via intermediates, such as suspension systems [12] or innovative nanofibrous mats [13]. Moreover, from a chemical point of view, graphene can be regarded as the nano-analogue of the long carbon fibres used for the composite production, in a nano- to macro-world homogeneous approach. Thus, the modification of a carbon fibre composite matrix by addition with Graphene and Related Materials (GRMs) might result in a twofold benefit: on one hand it might help improving the matrix bulk properties $[14,15]$, on the other hand the nano-additive has an intrinsic affinity towards carbon fibres. Up to now, indeed, the only examples reporting commercial application of Graphene are in composite materials, such as in tennis rackets [16]. Tough the material's benefits are unmistakable, there is still a lot to understand in the effect GRM might impart on the composite 
processing, production and final materials behaviour, in order to fully exploit the huge potential of Graphene and Related Materials.

Hence, in the present work, the modification of a commercial two-components epoxy resin formulation, presently used for long fibres composite production, has been modified by addition of GRMs, in particular Graphene (G) and Graphene Oxide (GO). Different dispersion methods were taken into account in order to produce stable long lasting dispersion of the GRMs that can withstand a commercial shelf life. Besides the evaluation of the actual reinforcing effect of the carbon-based nano-fillers, the modified matrices were used to evaluate their basic kinetics parameters, as a function of GRMs addition methods. The reason behind this investigation stems from the observation that both Graphene $[10,17,18]$ and, to a lesser extent, Graphene Oxide [19], are able to modify thermal conductivity of the polymer matrix where they are dispersed, while GO is also able to participate in the curing process via the oxidized surface and edge moieties [20]. These contributions might thus alter the overall curing process, and when these modified resins are used in conditions as demanding as the production of thick composites, they might lead to unexpected effects. Since to the best of the Authors' knowledge, there is no literature reporting the modelling of the industrial behaviour of GRM modified matrices in composite production, experimentally obtained kinetic data were thus used to simulate the curing profile, in particular when the modified epoxy systems were to be applied for the production of TCFRCs, in order to evaluate the influence of GRMs on the overall process and their compatibility with an industrial production.

\section{Experimental}

\subsection{Materials}

Epoxy resin components, prepolymer ElantTech EC157 (named R hereafter) and hardener ElanTech W61 (named H hereafter) were kindly supplied by ELANTAS Italia s.r.l. Graphene (G) and Graphene Oxide (GO) were obtained by GNext (Bologna - Italy). Tetrahydrofuran (THF) was purchased by Aldrich and used without further purification.

\subsection{Preparation of $G$ and $G O$ suspensions in the hardener ( $H-G$ and $H-G O$ )}

Graphene $(33.0 \mathrm{mg})$ and graphene oxide $(33.8 \mathrm{mg})$ were weighed in two different glass vials. Hardener $(10.0 \mathrm{ml})$ was added to each vial, then the vials were sealed in nitrogen atmosphere. Both suspensions were magnetically stirred for $24 \mathrm{~h}$ then sonicated in a sonicating bath at $37 \mathrm{kHz}$ at room temperature for additional $3 \mathrm{~h}$ to provide hardener suspensions named $\mathrm{H}-\mathrm{G}$ and $\mathrm{H}-\mathrm{GO}$ respectively. 
Graphene $(64.0 \mathrm{mg})$ and graphene oxide $(97.0 \mathrm{mg})$ were weighed in two different glass vials. Then THF was added to the vials ( $20.0 \mathrm{ml}$ to $\mathrm{G}$ vial and $32.3 \mathrm{ml}$ to $\mathrm{GO}$ vial); both the containers were closed and magnetically stirred for $24 \mathrm{~h}$. Then sonication in a sonicating bath at $37 \mathrm{kHz}$ at room temperature and magnetic stirring were alternated for 3 weeks, reaching an overall sonication time of $48 \mathrm{~h}$ to provide cG and cGO respectively, where "c" indicate that GRMs are suspended in a carrier solvent, namely THF. cG and cGO suspensions ( $3.7 \mathrm{ml}$ and $3.9 \mathrm{ml}$ respectively) were added each to $20 \mathrm{~g}$ of resin $\mathrm{R}$ weighed in a $100 \mathrm{ml}$ round bottom flask. THF was then removed fist in rotary evaporator then under high vacuum until constant weight to produce R-G and R-GO suspensions.

\subsection{Resin preparation}

The thermoset feed was prepared according to the technical data sheet, that suggests a mixing components in $\mathrm{R}: \mathrm{H}=100: 17$ weight ratio. The actual feeds are resumed in Table 1. As an example here is described the production of plain unmodified $\mathrm{R}+\mathrm{H}$ resin.

Table 1. Feed composition of plain resin $(\mathrm{R}+\mathrm{H})$ and nanocomposites reinforced with $\mathrm{G}$ and GO.

\begin{tabular}{lccccccc}
\hline \multicolumn{1}{c}{ Sample } & $\mathbf{R}$ & $\mathbf{H}$ & $\mathbf{R}-\mathbf{G}$ & $\mathbf{R}-\mathbf{G O}$ & $\mathbf{H}-\mathbf{G}$ & $\begin{array}{c}\text { H-GO } \\
(\mathbf{m l})\end{array}$ & $\begin{array}{c}\text { Actual GRM content } \\
\text { in the final resin } \\
(\mathbf{m})\end{array}$ \\
\hline Ref & 4.00 & 0.72 & 0 & 0 & 0 & 0 & 0 \\
G-a & 3.01 & 1.90 & 3.03 & 0 & 0 & 0 & 252 \\
G-b & 0 & 1.09 & 6.03 & 0 & 0 & 0 & 500 \\
G-c & 6.00 & 0.54 & 0 & 0 & 0.54 & 0 & 250 \\
G-d & 6.02 & 0 & 0 & 0 & 1.09 & 0 & 502 \\
GO-a & 1.53 & 0.55 & 0 & 1.54 & 0 & 0 & 255 \\
GO-b & 0 & 0.55 & 0 & 3.05 & 0 & 0 & 510 \\
GO-c & 6.01 & 0.54 & 0 & 0 & 0 & 0.54 & 251 \\
GO-d & 6.01 & 0 & 0 & 0 & 0 & 1.09 & 501 \\
\hline
\end{tabular}

$4.0 \mathrm{~g}$ of $\mathrm{R}$ and $0.72 \mathrm{ml}$ of $\mathrm{H}$ were poured in a glass vial, and the mixture was treated with magnetic and mechanical stirring. The vial was then degassed under high vacuum. The mixture was produced in a suitable amount to prepare DSC samples to be analysed either in dynamic or in isothermal mode, as well 
as samples for mechanical tests. DSC hermetic aluminium pans were filled, sealed and stored at $-18^{\circ} \mathrm{C}$ in order to prevent the curing reactions to start before the testing. The remaining mixture was then poured in an aluminium mould with six $200 \times 5 \times 2 \mathrm{~mm}$ parallel cavities treated with a releasing agent and cured according to the optimal curing cycle reported in the datasheet, $24 \mathrm{~h}$ in isotherm at $40^{\circ} \mathrm{C}$, then the temperature was constantly raised up to $120^{\circ} \mathrm{C}$ in an $8 \mathrm{~h}$ timespan and finally the mold was kept isothermally at $120^{\circ} \mathrm{C}$ for further $6 \mathrm{~h}$. Once the mould reached room temperature, the resin stripes were released.

Resins obtained from H-G and H-GO are named G-a/d and GO-a/d respectively, as described in Table 1. For the sake of comparison a plain $\mathrm{R}+\mathrm{H}$ sample was also produced as reference, which is labelled as Ref.

\subsection{Equipment and Procedures}

Thermogravimetric (TGA) measurements were carried out using a TA Instrument SDT Q600 (heating rate $20^{\circ} \mathrm{C} / \mathrm{min}$ ) on $10 \mathrm{mg}$ samples under nitrogen atmosphere (flow rate $100 \mathrm{ml} / \mathrm{min}$ ). $\mathrm{T}_{5 \%}$ is the temperature at which each sample shows a 5\% weight loss and it is taken as indication of the starting thermal degradation. Dynamic mechanical analysis (DMA) was performed with Perkin Elmer DMA 7 analyzer in three point bending configuration, with a heating rate of $3^{\circ} \mathrm{C} / \mathrm{min}$ up to $160^{\circ} \mathrm{C}$ and 1 $\mathrm{Hz}$ oscillation frequency. Tensile test was carried out at room temperature with an Instron-type tensile testing machine (REMET TC10). The crosshead speed was $5 \mathrm{~mm} / \mathrm{min}$ and the initial gauge length was $25 \mathrm{~mm}$. The provided results are the average of a set of 5 measurements per each formulation. Surface fracture images were taken with a Scanning Electron Microscope (SEM) ZEISS EVO 50 EP in Environmental mode with $\approx 100$ Pa pressure in the chamber. DSC measurements were carried out on a TA Instruments Q2000 DSC Modulated apparatus equipped with RCS cooling system. In dynamic runs every sample $\left(5 \mathrm{mg}\right.$ ) was heated from $0^{\circ} \mathrm{C}$ to $200^{\circ} \mathrm{C}$ twice at $20^{\circ} \mathrm{C} / \mathrm{min}$ in nitrogen atmosphere, with an intermediate cooling run carried out at $20^{\circ} \mathrm{C} / \mathrm{min}$. The measurements in isothermal mode were carried out (only on the plain $\mathrm{R}+\mathrm{H}$ sample and on the 500pm GRM containing modified resins) inserting the sample in the furnace pre-heated at the desired isothermal curing temperature $\left(\mathrm{T}_{\text {iso }}=50\right.$, $60,70,80,90,100,110^{\circ} \mathrm{C}$ ) for different amount of times, in order to complete the exothermic peak (from 30 to $240 \mathrm{~min}$ ). After the isotherm is over the sample is quenched down to $0^{\circ} \mathrm{C}$ and a dynamic heating run at $20^{\circ} \mathrm{C} / \mathrm{min}$ is carried out up to $200^{\circ} \mathrm{C}$.

The 2D-mesh used for the modeling of the cure dynamics was prepared with Hypermesh software and it represents the cross section of the component at its thickest section (50mm thickness and $200 \mathrm{~mm}$ width). The simulated composite is assumed to be composed of 30\%wt resin and $70 \%$ wt unidirectionally aligned carbon fiber. For the simulation the Curing module of PAM-RTM was used, a commercial 
software developed by ESI-Group which simulates the curing process with a finite element approach [21]. A temperature profile was fixed at the inner and outer layers of nodes, representing respectively the inside bagging film and the outside surface of the mould, both in contact with the air inside the autoclave. Some standard characteristic values such as the density and specific heat capacity for each material involved were obtained from literature [22, 23]; thermal conductivity of the final composite strongly depends on the fiber arrangement, type of carbon fiber and resin, fiber volume, fiber/matrix adhesion, etc [24]. The overall transverse thermal conductivity value adopted for the simulation is set at $0.8 \mathrm{~W} / \mathrm{mK}$, this value taking into account both the resin components and some contribution of the long carbon fibers and is intended just as an example that could fit in with the many values that can be retrieved in the literature $[24,25]$ : the purpose is to choose a reference value, common for the different simulations, in order to outline the differences owed to resin reactivity in the very same conditions. Given their low concentration (few hundreds of ppm) we assumed that the GRM contributed only minimally to heath conduction. The kinetics and other reaction parameters typical of the different resins were obtained from the analysis of experimental DSC data.

\section{Results and Discussion}

\subsection{GRM dispersion and resin production}

In order to impart the strongest reinforcing effect on the polymer substrate, the graphenic derivatives have to be well exfoliated and homogeneously dispersed in the matrix that, in the present case, is a twocomponents commercial epoxy resin. Both $\mathrm{G}$ and $\mathrm{GO}$, obtained as a thin black powder, have to be conveyed in the epoxy system prior to the curing. G powder is composed of platelets with $5 \mu \mathrm{m}$ lateral dimension and 2-8 nm thickness., while GO, produced by a modified Hummers' method, in the original solution contained over $90 \%$ of monolayer sheets, with a C/O mass ratio around 1 and an average lateral sheets dimension of about $20 \mu \mathrm{m}$. Though in principle it is possible to add the GRM powder to the already mixed commercial components, in order to obtain a potentially commercial product, dispersion was addressed either using one of the two commercial products as suspending agents or using a third party acting as a carrier to be removed before the two components are mixed and the cross-linking process begins. Attempts at dispersing GRMs in different suspension media were all carried out by alternating stirring and sonication, with the aim of producing stable long-lasting dispersions of the nano-additives that can withstand a commercial optimal shelf life.

Epoxy thermosets are very complex systems, whose final properties and performances are strongly affected by a number of factors that may vary the curing process. Since the dispersion procedure might affect the way different GRMs, namely $\mathrm{G}$ and GO, can interact with the resin components during cross linking, different dispersion approaches as well as different nano-additives' concentrations were 
evaluated, together with their effects on thermo-mechanical properties of the final nanocomposite. As the pre-polymer $\mathrm{R}$ and the hardener $\mathrm{H}$ display significantly different viscosities at room temperature ( $\mathrm{R}$ : 500/600 mPas; H: 5/15mPas from technical datasheet) the dispersion approach was adapted to the medium condition. Hence it was chosen to directly disperse the GRMs in $\mathrm{H}$ (hereafter defined as $\mathrm{H}-\mathrm{G}$ or $\mathrm{H}-\mathrm{GO}$;) while, in order to obtain a suitable dispersion in $\mathrm{R}$, the graphenic nano-additives were first suspended in a solvent, then the resultant suspension was added to the prepolymer $\mathrm{R}$, and finally the carrier solvent was evaporated under vacuum. These samples are hereafter labelled as R-G or R-GO. Each time a mixing step was required, it was always followed by a sonication step that should help the intimate mixture of the components. GO is well dispersible in water and in typically hydrophilic solvents, such as $N$-methyl-2-pyrrolidone (NMP), N,N-dimethylformamide (DMF), and tetrahydrofuran (THF) [26]. Among all the suitable solvents, THF was adopted in the present work because it is the only aprotic medium characterized by a low boiling point $\left(\mathrm{T}_{\text {ebNMP }}=202^{\circ} \mathrm{C}, \mathrm{T}_{\text {ebDMF }}=153^{\circ} \mathrm{C}, \mathrm{T}_{\mathrm{ebTHF}}=66^{\circ} \mathrm{C}\right)$, both essential features in order for the carrier solvent to not interfere with the epoxy resin components' reactivity and to be taken away once the GRM nanofillers are homogeneously dispersed in the prepolymer phase. The produced $3 \mathrm{mg} / \mathrm{ml}$ GO suspension in THF (labelled as cGO) was checked after 4,20 , and 52 weeks, displaying still a good homogeneous aspect. Analogously, the attempts to disperse GO in $\mathrm{H}(3 \mathrm{mg} / \mathrm{ml})$ lead again to a well dispersed long-lasting suspension that could be used directly to produce the final nanocomposite thermoset. G, on the contrary, is well renown to be difficult to disperse, and it is known that the best suspending solvent are high boiling point ones, such as cyclopentanone $\left(\mathrm{T}_{\mathrm{eb}}=130^{\circ} \mathrm{C}\right)$ cyclohexanone $\left(\mathrm{T}_{\mathrm{eb}}=155^{\circ} \mathrm{C}\right)$ or $N$-methyl-2-pyrrolidone $\left(\mathrm{NMP}, \mathrm{T}_{\mathrm{eb}}=202^{\circ} \mathrm{C}\right)$ [27], none of them complying with the requirements early put forward for a good carrier solvent. Accordingly, when trying to disperse $\mathrm{G}$ in the same media used for GO, i.e. THF and $\mathrm{H}$ ( $\mathrm{cG}$ and $\mathrm{H}-\mathrm{G}$, respectively), the suspension lasted for just seconds to tenths of seconds before nanofillers started to precipitate. Nevertheless, in order to obtain thermosets analogues to the ones containing GO, both R-G and H-G were produced and used directly after production. In both cases, i.e. using G or GO as nanofillers, the most concentrated dispersion of graphenic derivative was first obtained, and this master batch suspension was further diluted in order to obtain a lower GRM load in the final thermoset (500ppm, and 250ppm respectively, as reported in Table 1).

The nanoscale morphology of $\mathrm{cG}$ and cGO were observed using atomic force microscopy (AFM) after spin coating from the THF dispersions onto a flat silicon surface. G nano-sheets were characterized by an average thickness between 2 to $8 \mathrm{~nm}$ and a lateral sizes below $5 \mu \mathrm{m}$. GO nano-sheets had a thickness of about $1,1 \pm 0,2 \mathrm{~nm}$ and a lateral size larger than $20 \mu \mathrm{m}$ ). The measured thickness of GO agrees well with the one typical of well-exfoliated monolayers [28], while cG sheets are aggregated in multilayer stacks composed of 6-12 layers, featuring small lateral size due to the prolonged sonication needed to attain a 
decent dispersion of the nanofiller in THF. The graphene material, thus, being composed of multiple layers, shall be better defined as graphite nanoplatelets (GNP). AFM measurements performed on $\mathrm{H}-\mathrm{G}$ and H-GO did not give significant results due to the presence of the amine-based hardener which cannot be successfully removed.

All the suspensions were prepared in order to ensure comparable GRM loads referred to the final thermoset compositions (Table 1). For the sake of comparison a plain $\mathrm{R}+\mathrm{H}$ resin, with no GRM addition, was also produced as a reference material (Ref).

All the $\mathrm{R}+\mathrm{H}$ mixtures, prepared according to the technical datasheet (Table 1), were poured in a tailormade open multi-channel aluminium mould and subjected to the optimal curing cycle (from technical datasheet) working in atmospheric pressure: samples were cured at $40^{\circ} \mathrm{C}$ for $24 \mathrm{~h}$ then, after raising the temperature up to $120^{\circ} \mathrm{C}$ at a constant $10^{\circ} \mathrm{C} / \mathrm{h}$ heating rate, resins were kept curing at $120^{\circ} \mathrm{C}$ for additional 6h. The obtained materials appeared well cured and homogeneous, with good transparency and a greyish colour due to the presence of the nanosheets.

\subsection{Graphene modified resin characterization}

All the $G$ containing resins $(\mathrm{G}-\mathrm{a} / \mathrm{d})$ were subjected to thermo-mechanical characterization. TGA measurements, carried out on all the nanocomposites as well as on the plain unloaded resin $\mathrm{R}+\mathrm{H}$, displayed no significant differences in thermal stability, as reported in Figure 1, in terms of temperature of $5 \%$ weight loss $\left(\mathrm{T}_{5 \%}\right)$. The DSC analysis of all the samples display only a high-T (well above RT) stepwise transition ascribed to the glass transition of the resin $\left(\mathrm{T}_{\mathrm{g}}\right)$; this transition is often overlapped with an enthalpic relaxation that hampers a correct evaluation of the $T_{g}$. No exothermic signal was detected in the samples, indicating that the curing reaction (a strongly exothermic process) was complete after the $120^{\circ} \mathrm{C}$ treatment.

With the aim of providing a reliable evaluation of the glass transition of the resin, DMA measurements were carried out on both the reference plain $\mathrm{R}+\mathrm{H}$ resin and on the $\mathrm{G}$ containing nanocomposites (see Figure 1). The DMA spectra of all the analyzed samples show a main relaxation process (a) and a lowertemperature secondary dissipation region (b), the latter centred for all the materials at $-52^{\circ} \mathrm{C}$, while the former relaxation's position depends on the actual sample composition (Figure 1). Different origins for the secondary relaxation phenomenon can be invoked, the most probable related to the local relaxations of small molecular side groups and/or local rearrangements of some adsorbed water molecules bound to the hydrophilic residues of the epoxy resin, which are mobile at this temperature $[29,30]$. In both cases, $G$ addition in hundreds of ppm is not expected, and indeed not observed, to impact on the position and entity of such local events. On the contrary, $\mathrm{T}_{\mathrm{a}}$ of the $\mathrm{G}$ containing resins moves to a higher temperature with 
respect to plain Ref as a function of the nanofillers quantity: the relaxation widens and the intensity decreases, as a consequence of the hindered chain mobility due to the contact between the polymer backbone and the graphenic nanosheets that not only limits molecular mobility, but also broadens the relaxation time spectrum due to stronger interactions. In particular it can be observed that the highest impact on the main relaxation event is achieved with the highest $G$ content (500ppm), while a lower nanofiller load does not attain significant modifications. Moreover, the data reported in Figure 1 show the importance of the dispersion methodology: indeed, the dispersion of graphene nanosheet in the resin precursor with the help of a carrier solvent has a limited effect on the chain mobility, while the same nanofiller dispersed directly in the hardener is able to increase $\mathrm{T}_{\mathrm{a}}$ from $101^{\circ} \mathrm{C}$ of the plain $\mathrm{R}+\mathrm{H}$ up to $117^{\circ} \mathrm{C}$ for G-d.

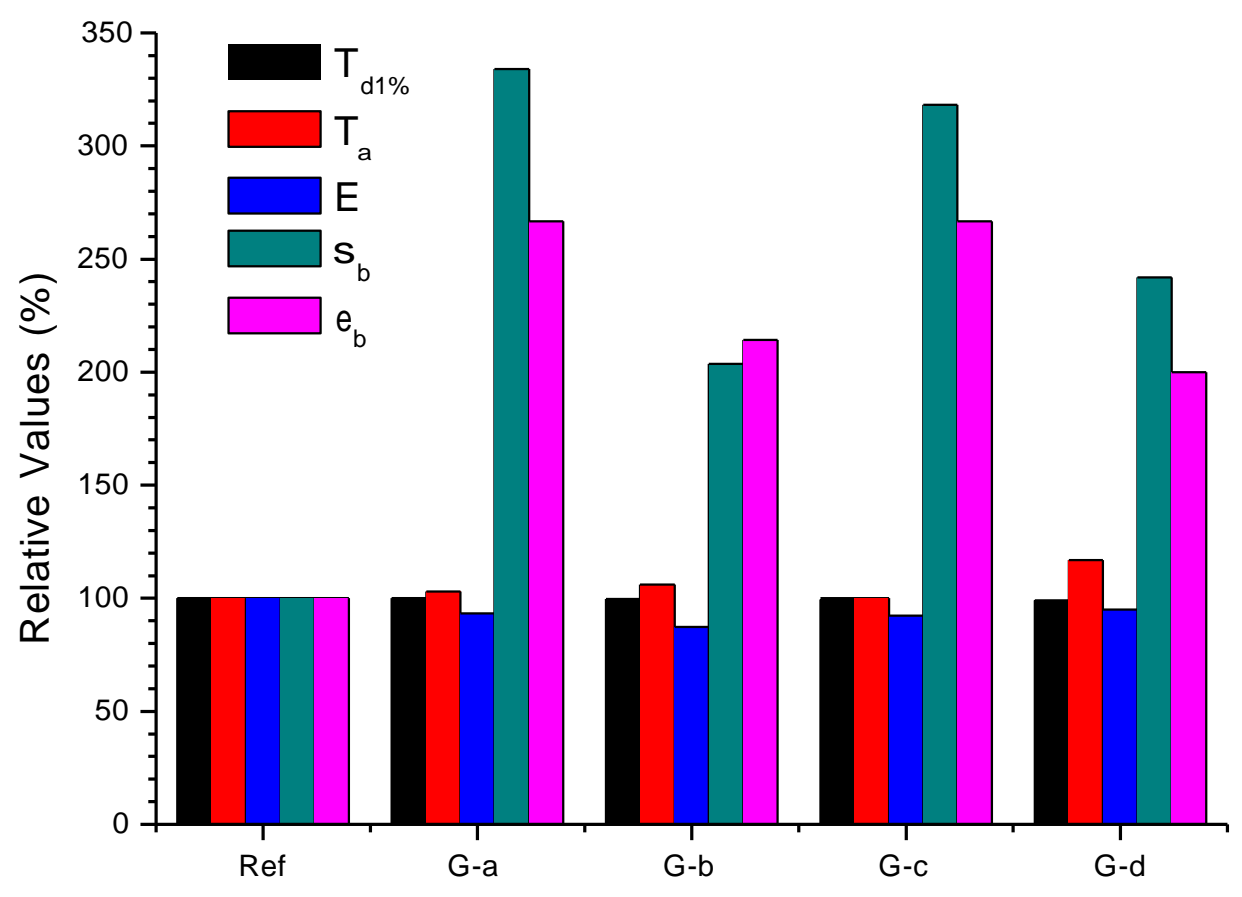

Figure 1. Thermo-mechanical properties of $\mathrm{G}$ containing resins (G-a/d) expressed as $\%$ variation respect the plain formulation (Ref). For the full data set, please refer to SI material.

In order to highlight the effect of the nanofiller on the resins' mechanical properties, the stress/strain behavior of the $\mathrm{G}$ modified materials was measured and compared to the plain $\mathrm{R}+\mathrm{H}$ reference sample: tensile modulus $(E)$, strength $\left(\mathrm{s}_{\mathbf{b}}\right)$ and elongation at break $\left(\mathrm{e}_{\mathrm{b}}\right)$ are reported in Figure 1 as relative variation with respect to the values obtained for the pristine reference resin. It is well known that plain cured epoxy resins are quite brittle materials, and indeed Ref shows a poor elongation at break and a fairly high Young's Modulus. The Modulus of the G modified resins is not significantly affected by the addition of graphene derivatives to the commercial epoxy resin formulation, while both stress and elongation at break 
increase from twice up to more than 3 times the original values. Hence, though the stiffness of the material is not significantly affected, the toughness is increased. It is worth noting that all samples show their best performance with 250ppm G load. The drop of performance when the nanofiller concentration increases from $250 \mathrm{ppm}$ to $500 \mathrm{ppm}$ can be attributed to the exceeding of the optimal suspension concentration, that is strongly dependent on the environmental conditions. The extremely low concentration allowed for $\mathrm{G}$ before aggregation phenomena take place, is quite expected, due to the previously discussed poor compatibility of graphene sheets with hydrophilic environments such as the hardener or THF that might hamper its reinforcing ability.

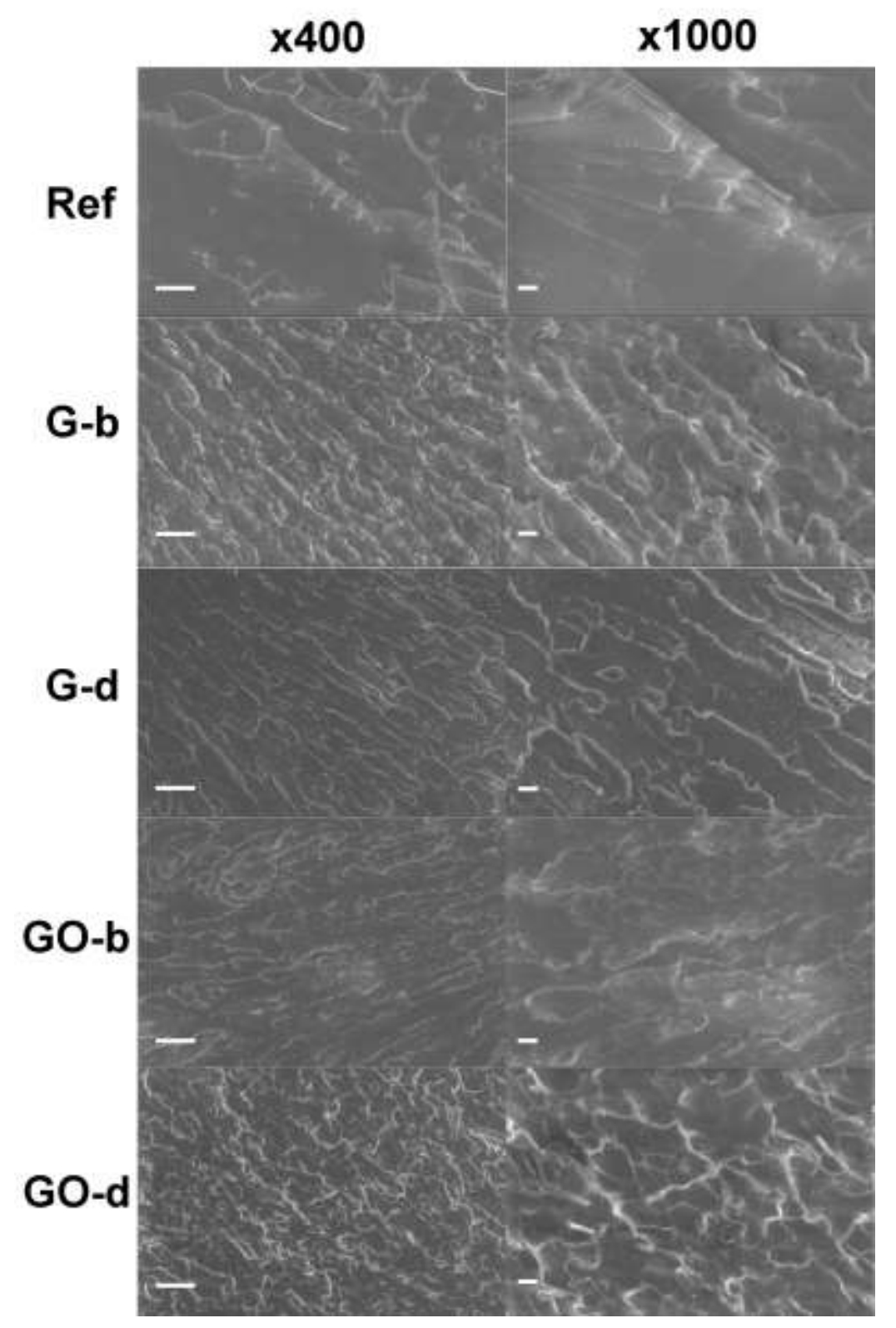


Figure 2. SEM micrographs of the fracture surface at different magnification ( $x 400$, scale bar $100 \mu \mathrm{m}$, and x1000, scale bar $20 \mu \mathrm{m}$ ) of Ref, G-b, G-d, GO-b, and GO-d.

Nevertheless, the reinforcing effect of graphene derivatives is clearly highlighted in Figure 2, where the fracture surfaces of the plain epoxy resin, Ref, and of the nanocomposites reinforced with different quantities of graphene are reported. The SEM micrographs of tensile-failed specimens (Figure 2) reveal, as expected, that the fracture surface of the reference plain epoxy resin (Ref) shows typical characteristic of brittle fracture. The surface is smooth with uninterrupted crack propagation and sharp edges. On the contrary, the fracture surfaces of the $\mathrm{G}$ containing resins are rough with ridge patterns. The roughness of the surface is the result of crack path deflections that account for a more ductile nature of the crack. Hence addition of the nanofillers modifies the fracture surface appearance with more sign of local plastic deformation and crack deflections. A similar behavior is observed for all the nanocomposites, though no significant correlation of the roughness can be established with the $\mathrm{G}$ load in the samples, accounting for the fact that, when present and well dispersed, the mere presence of the G nanosheets is able to deflect the propagating crack, thus enhancing the toughness of the modified resin.

\subsection{Graphene Oxide modified resins characterization}

While $\mathrm{G}$ reinforced resins displayed some improvements with respect to the plain formulation, the well dispersed GO solutions are expected to outperform them. Hence the modified resins were analysed and DSC once again confirmed the completeness of the curing process; moreover, as depicted in Figure 3, addition of GO to the resin formulation was observed to leave thermal stability of the materials almost unaffected. 


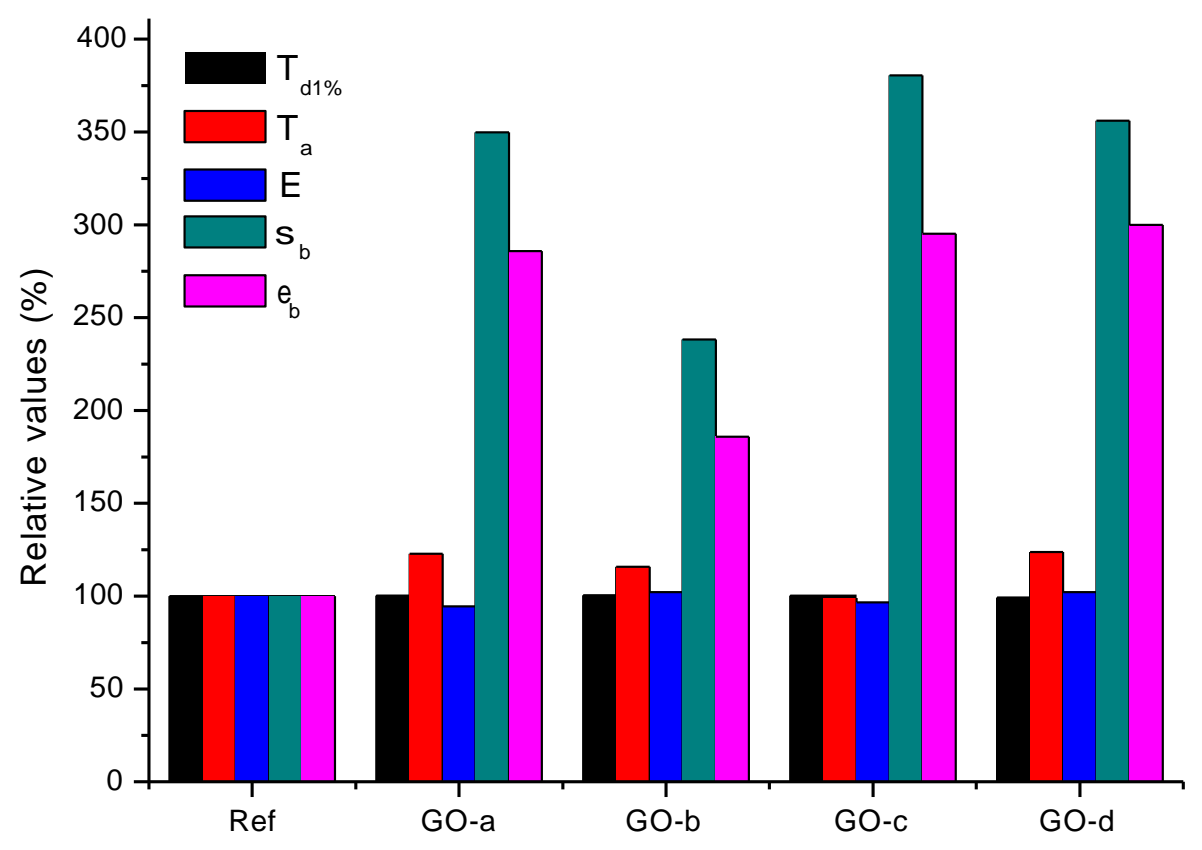

Figure 3. Thermo-mechanical properties of GO containing resins expressed as $\%$ variation respect the plain $\mathrm{R}+\mathrm{H}$ formulation (Ref). For the full data set, please refer to SI material.

The DMA spectra of all the analysed samples show again a composition dependent main relaxation process (a) and a lower-temperature secondary dissipation region (b), centered for all the materials at $-52^{\circ} \mathrm{C}$. When GO nanosheets are used as reinforcement, they seem to be able to affect the final resin chain mobility to a higher extent that $\mathrm{G}$ (Figure 3), reaching Ta up to $124^{\circ} \mathrm{C}$ and $125^{\circ} \mathrm{C}$ for GO-b and GO-d respectively. The stronger effect of GO as compared to G can be ascribed to a much more effective interaction with the polymer matrix, due to the presence of a number of hydrophilic moieties on the nanosheets surfaces. Moreover, the more effective exfoliation and dispersion of GO as compared to G allow a more uniform dispersion of the nanosheets in the polymer, thus truly attaining a nano-composite. Stress/strain mechanical tests were carried out on the GO modified resins and relative variation of their tensile modulus $(E)$, strength $\left(\mathrm{s}_{\mathrm{b}}\right)$ and elongation at break $\left(\mathrm{e}_{\mathrm{b}}\right)$ are reported in Figure 3 with respect to the values obtained for the pristine reference resin. Once again the stiffness of the material is not significantly affected, while the toughness is generally increased, definitely more than when graphene is used. It is worth noting that when GO is conveyed into the resin precursor via a carrier solvent (GO-a and $-b)$, the best performance occurs at 250ppm GRM load, as observed for the poor G suspensions. When, instead, GO is loaded directly into the hardener (GO-c and -d) some good performance is attained both at 250ppm and at 500ppm nanofillers content, with an increase of $\mathrm{s}_{\mathrm{b}}$ up to almost four times vs. the plain resin and of $e_{b}$ of almost three times. The ability of GO to form, upon curing, covalent bonds with the resin via the 
oxygen rich moieties on its surface and edges might be one of the reasons of its capacity to give a larger reinforcing action, acting as a multifunctional cross-linker. The drop of performance of GO, when suspended in the resin via THF, can be attributed to the exceeding of the optimal suspension concentration. It might be hypothesised that when the THF carrier solvent is removed, the epoxy prepolymer environment reaches a more hydrophobic character, thus causing segregation of the nanosheets at even slightly high concentration such as $500 \mathrm{ppm}$. On the contrary, when GO is dispersed into the more hydrophilic hardener, it is further conveyed into the resin within the same medium, thus assuring a convenient environmental condition, that does not hamper the previously obtained good dispersion, hence leading to the optimal interaction of the reinforcement with the resin components, even during the curing.

The SEM micrographs of tensile-failed GO modified specimens (Figure 2 and Figure S1) reveal, the same roughness with ridge patterns as observed for $\mathrm{G}$ reinforced resins. No differences arise in the look of the fractured specimens when the carbon nanofiller is supposed to be covalently connected with the polymer matrix. When the nanosheets can be efficiently and covalently bound to the surrounding matrix however, the reinforcing effect is stronger as assessed by the previously discussed mechanical tests [31].

\subsection{Simulation of the curing process and kinetics parameters evaluation}

Since the thermomechanical behaviour of the modified resins suggests that in the presence of nanofillers, in particular GO, some covalent bonds with the graphenic derivative might occur, this might also affect the overall reaction kinetics of the resin curing. Hence, in order to verify it, the crude mixtures with the highest content of nanofillers, i.e. 500ppm (G-b, G-d, GO-b, and GO-d), were subjected to a heating scan in DSC. Data reported in Table 2 show that nanofillers actually affect the curing process with respect to the reference plain sample Ref: in particular GO-b, the sample where GO was delivered into the resin precursor via a carrier solvent, shows an exotherm with the maximum located at a lower temperature while the associated enthalpy decreases and G-d, the sample where G was delivered directly via hardener, shows a strong increase in curing enthalpy with a slight increment of the temperature peak. All the other samples show an increase of the exotherm peak location, while the reaction enthalpy is almost unaffected.Thus the cure kinetics of the modified resins were investigated in order to obtain kinetics parameters which will then be applied to simulate the industrial curing cycle of the nanocomposites, in the case the different formulations were used for a thick carbon fibers composite production in autoclave. Evaluation of a commercial epoxy resin formulation kinetics is a complex matter, owing to the number of competitive processes that occur simultaneously, influencing each other. Therefore a phenomenological approach was adopted $[32,33]$ in order to provide an estimation of the overall sum of these processes as a single occurring phenomenon: the obtained data are thus referred as apparent kinetics parameters $[34,35]$ 
(activation energy $E_{a}$ and reaction order $m+p$ ). In the present work, kinetic parameters were evaluated with the isothermal DSC runs approach (see SI for extensive experimental and mathematical procedures). The obtained values show $m$ to be almost constant with $\mathrm{T}$, while $p$ is definitely more sensitive to the temperature increase, as reported for both the plain and the modified resins in Table 2.

The type and number of competitive chemical reactions, the involved reaction enthalpies, the thermal conductivity of the components, and the specific heat of each involved material may affect the curing of a composite object acting on the curing temperature profile, which in turn impacts on the reaction kinetics, and finally even on the mechanical properties, whenever an internal stress is created owing to differences in the curing behavior of neighbouring spots in the bulk. Hence, even if the apparent kinetic parameters characterizing the different resins are known, this is not enough to predict the overall performance of the final object based on these resins, as the cure may affect many different aspects of the object itself. We thus used computer simulations to highlight differences in the overall curing process when modified resins are industrially applied. Particular attention was devoted to the evaluation of the early stages of the industrial curing process simulation, where the most exothermic phenomena occur, that are considered the most critical during the production of a thick composite object as the selected model.

Table 2. Characteristics of the curing exotherm peak determined in dynamic DSC run and kinetics parameters $\left(m+p, E_{a}\right)$ evaluated from isothermal DSC measurements for the plain Ref resin and for the 500pm GRM containing modified resins (see SI for details).

\begin{tabular}{|c|c|c|c|c|c|c|c|}
\hline \multirow{2}{*}{ Sample } & \multirow{2}{*}{$\begin{array}{l}\boldsymbol{T}_{\text {peak }} \\
\left({ }^{\circ} \mathbf{C}\right)\end{array}$} & \multirow{2}{*}{$\begin{array}{c}\boldsymbol{\Delta} \boldsymbol{H}_{\mathrm{T} d y n} \\
(\mathbf{J} / \mathbf{g})\end{array}$} & \multicolumn{2}{|c|}{$m=\left(\mathbf{a}^{*} T_{i s o}\right)+\mathbf{b}$} & \multicolumn{2}{|c|}{$p=\left(c^{*} T_{i s o}\right)+d$} & \multirow{2}{*}{$\begin{array}{c}E_{a} \\
(\mathrm{~kJ} / \mathrm{mol})\end{array}$} \\
\hline & & & $\mathbf{a}$ & b & c & d & \\
\hline Ref & 120 & -395 & 0.0013 & -0.3513 & 0.0131 & -3.5374 & 65 \\
\hline G-b & 124 & -398 & 0.0019 & -0.4694 & 0.0159 & -4.6073 & 64 \\
\hline G-d & 124 & -531 & 0.0017 & -0.4256 & 0.0151 & -4.2894 & 71 \\
\hline GO-b & 115 & -405 & 0.00025 & 0.1714 & 0.0079 & -1.8818 & 64 \\
\hline GO-d & 122 & -383 & 0.00016 & 0.1852 & 0.0149 & -4.1823 & 66 \\
\hline
\end{tabular}

The modelling of the overall curing process can be of valuable help, using a specific dedicated software that takes into account all the previously discussed parameters and their complex interplay. The obtained kinetic parameters describe well the reaction behavior until a high degree of cross-linking is reached. Then a diffusion equilibrium sets in, slowing down the reaction rate, hence the model curves diverge from the experimental ones in this last section since this diffusional aspect is not taken into account in the presently applied Kamal-Sourour model [2, 34, 36]. However, it is exactly the initial stage of the curing process, when the reaction rate is driven by the intrinsic reactivity of the involved reactants and which is 
correctly represented by the calculated kinetic parameters, the most interesting for the present study, since the simulation is mainly intended to highlight differences introduced by the GRMs behaving as curing reactants. Hence the cure of a thick object, a beam of infinite length and 200x50mm section composed of $70 \%$ wt unidirectionally aligned carbon fibers and $30 \%$ wt resin, was simulated. The noticeable thickness $(50 \mathrm{~mm})$ brings in all the problems associated with the thick composites production, as earlier discussed in the introduction.

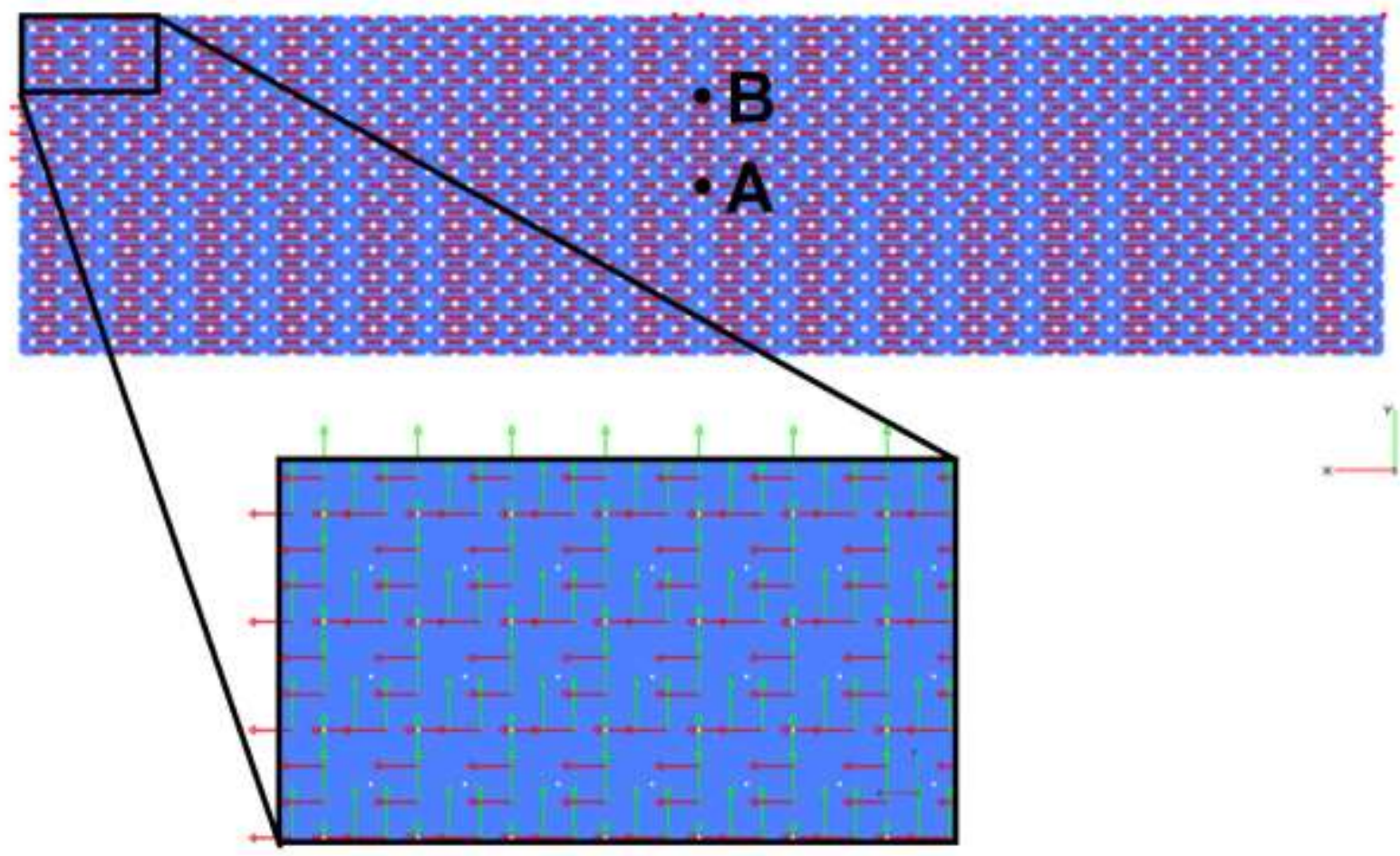

Figure 4 Finite element representation of the composite beam section modeled. A and B represent the positions of theoretical sensors measuring the curing temperature profile, placed at $25 \mathrm{~mm}$ and $12.5 \mathrm{~mm}$ from the outer boundary respectively. In the focus green and red arrows represent the heat propagation along the carbon fiber axis and across them respectively, while withe dots represent nodes.

In Figure 4 the section of the modelled object is reported, with its finite elements subdivision, as required by the PaN-RTM simulation software. Every single element is treated as a portion of the object exchanging heat from neighbouring elements at the nodes, as represented by the white dots in Figure 4, which are designed to be $0.4 \mathrm{~mm}$ apart. The effect of heat generation and propagation is thus summed stemming from thermal and kinetic parameters input. Since the carbon fibers are characterized by a definitely higher thermal conductivity, at least along the fiber axis, with respect to the resin [25], in the insert in Figure 4 arrows are depicted to address the different conditions. In particular red arrows account 
for heat propagation along the fiber axis, that is considered to be based on the carbon fiber properties, while the green ones describe heat conduction perpendicular to the fiber axis, and the value is set to be that of the resin. Since the GRM are below their percolation threshold [17, 19, 37, 38], for the modelling purpose they are assumed to not be contributing to the overall heat conduction, or in the case they do contribute, their impact will be considered within the already calculated resin kinetic parameters.
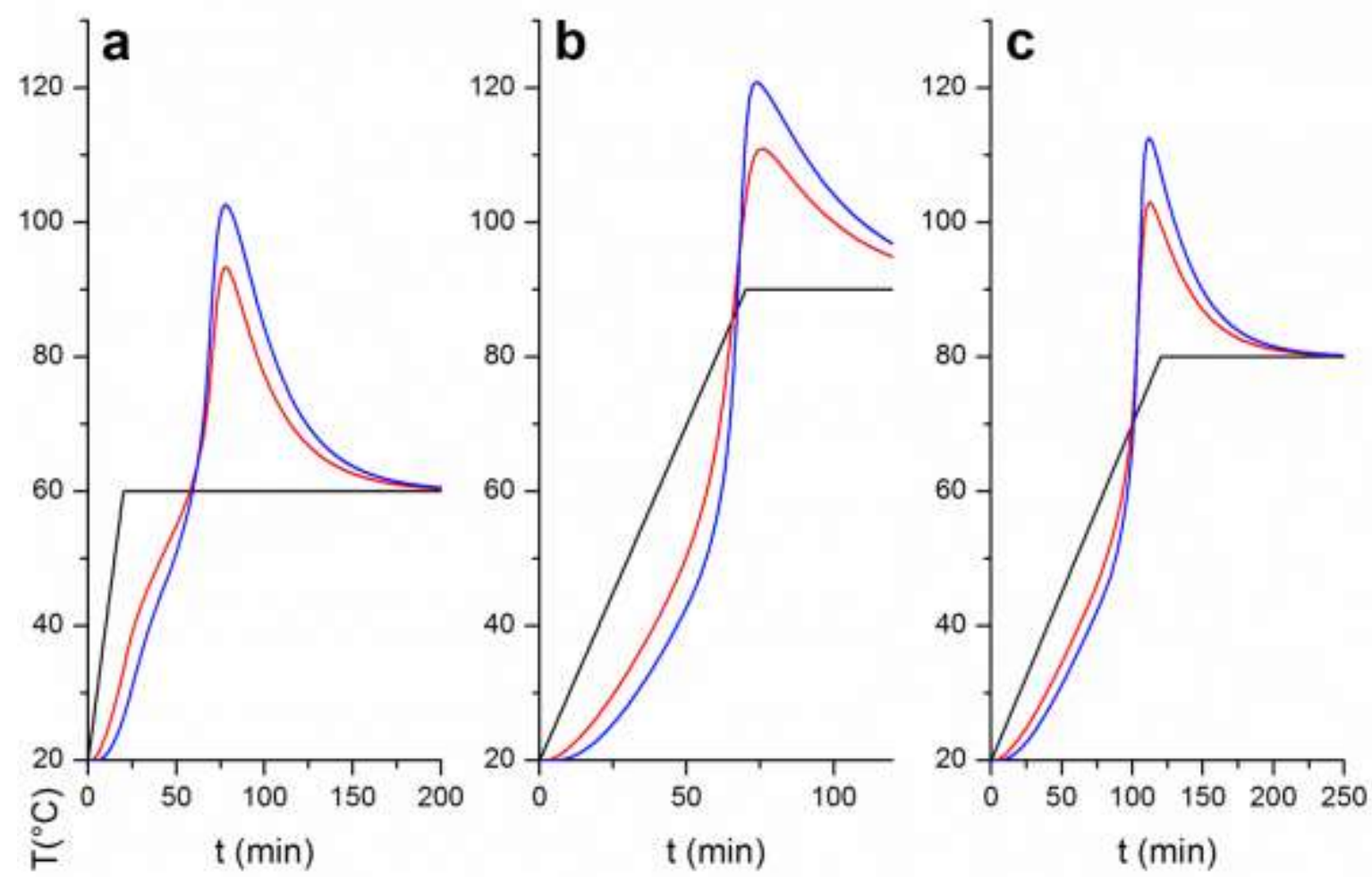

Figure 5 Simulated temperature profiles in the initial stage of the curing process of a $50 \mathrm{~mm}$ thick CFRP evaluated at $25 \mathrm{~mm}$ (blue line) and at $12.5 \mathrm{~mm}$ (red line) depth. The simulated curing profile is obtained when the heating process described by the black line is applied. In particular different heating rate and Isothermal temperatures are applied: a) heating rate $2^{\circ} \mathrm{C} / \mathrm{min}$ and $\mathrm{T}_{\text {iso }}=60^{\circ} \mathrm{C} ; \mathrm{b}$ ) heating rate $1^{\circ} \mathrm{C} / \mathrm{min}$ and $\mathrm{T}_{\text {iso }}=90^{\circ} \mathrm{C} ; \mathrm{c}$ ) heating rate $0.5^{\circ} \mathrm{C} / \mathrm{min}$ and $\mathrm{T}_{\text {iso }}=80^{\circ} \mathrm{C}$.

Different attempts at setting a convenient curing program were addressed considering just the plain $\mathrm{R}+\mathrm{H}$ resin formulation, and the obtained temperature profiles were simulated at two theoretical sensing locations, indicated as A and B in Figure 4, placed at $25 \mathrm{~mm}$ and $12.5 \mathrm{~mm}$ respectively from the external surface of the beam. As a first heating step of the process, the one more affected by exothermic phenomena, different heating rates were tested reaching different isothermal temperature; the simulated temperature profile of such first step is reported in Figure 5. The imposed heating program is also displayed in the plot, for the sake of comparison, and is considered as the temperature imposed to the 
beam from the outside. The simulated instant temperature at $\mathrm{A}$ and $\mathrm{B}$ indicates how the exotherm of the reaction can deviate the actual cure temperature profiles from the designed one, when the curing introduces heat to the system. At the highest heating rate $\left(2^{\circ} \mathrm{C} / \mathrm{min}\right)$, when reaching the first set temperature $\left(\mathrm{T}_{\mathrm{iso}}=60^{\circ} \mathrm{C}\right)$, a strong overheat is observed with respect to the programmed temperature, with the simulated temperature increasing up to $43^{\circ} \mathrm{C}$ in the case of the most internal sensor $\mathrm{A}\left(\mathrm{T}_{\mathrm{A}}\right)$ and about $33^{\circ} \mathrm{C}$ at the outer sensor $\mathrm{B}\left(\mathrm{T}_{\mathrm{B}}\right)$, as reported in Figure 5 -a. When lowering the heating rate at $1{ }^{\circ} \mathrm{C} / \mathrm{min}$ $\left(\mathrm{T}_{\text {iss }}=90^{\circ} \mathrm{C}\right)$ initial overheating phenomena were slightly reduced as shown in Figure 5-b, though the overall reached temperature is higher $\left(\mathrm{T}_{\mathrm{A}}=121^{\circ} \mathrm{C}, \mathrm{T}_{\mathrm{B}}=111^{\circ} \mathrm{C}\right)$. Hence, a last attempt was carried out lowering further the heating rate down to $0.5^{\circ} \mathrm{C} / \mathrm{min}$, and decreasing at the same time the attained temperature $\left(\mathrm{T}_{\text {iso }}=80^{\circ} \mathrm{C}\right)$, with the aim of reducing the maximum reached temperature, that might otherwise detrimentally affect the resin stability. As displayed in Figure 5-c, with this last attempt a similar overheat as in the previous $1{ }^{\circ} \mathrm{C} /$ min simulation was obtained, with $\mathrm{DT}_{\mathrm{A}}$ roughly around $32^{\circ} \mathrm{C}$ and $\mathrm{DT}_{\mathrm{B}}$ about $23^{\circ} \mathrm{C}$, though, owing to the lower $\mathrm{T}_{\text {iso }}$ set the overall temperature reached is lower than the previous situation $\left(\mathrm{T}_{\mathrm{A}}=112^{\circ} \mathrm{C}, \mathrm{T}_{\mathrm{B}}=103^{\circ} \mathrm{C}\right)$; moreover temperature profiles in the initial stages of the reaction, show a smaller deviation between sensor A and B. In all cases sensor A experiences a stronger overheat than $\mathrm{B}$, owing to the poorer heat conduction across carbon fiber axis, that makes heat produced upon curing accumulate at the deepest layers more and more with reaction proceeding. However, the minor is the deviation, the smaller are assumed to be the internal stresses potentially induced in the final composite. Hence, a curing process was developed starting from this first slow heating step and was then applied to the GRM containing resins.

Figure 6 shows a possible complete curing process temperature profile with a focus on the initial stage and the simulated temperature profiles of the plain Ref resin and the 500ppm GRMs modified ones: in this case, sensor A data only are reported, that is the most affected by overheating phenomena, but the same simulated effects are observed (data not shown) with smaller intensities, at sensor B position. All the formulations, as already observed in Figure 5, display a delay in the heating process with respect to the temperature profile applied, as reasonably expected owing to thermal inertia of the organic polymeric matrix, since the theoretical sensor A is far away from the outer surface where the heat is applied, and heat propagation from the mould occurs perpendicular to the fiber axes, i.e. along the poor heat conducting direction. The simulations reveal that, as expected, the nanofillers affect the temperature profiles. It was noticed that whenever GRMs are present, the overheat phenomena are smaller than in the plain $\mathrm{R}+\mathrm{H}$ resin. Nanocomposites however behave differently depending both on the GRM quality (G or GO) and its dispersion methodology. GO loaded resins both display strong overheat phenomena (maximum $\mathrm{T}_{\mathrm{A}}=100^{\circ} \mathrm{C}$ and $105^{\circ} \mathrm{C}$ for GO-d and GO-b respectively, Figure 6) that occur at different times. In particular, when GO is directly dispersed in the hardener (orange line in Figure 6), the highest reached 
temperature is $13^{\circ} \mathrm{C}$ lower than the plain resin (red line), but it is achieved in the same time $\left(t_{\text {peak }}=112^{\prime}\right.$ for Ref and $\mathrm{t}=114^{\prime}$ ' for GO-d). When GO is added via THF to the resin instead (blue line), heat accumulates more rapidly and the $\mathrm{T}_{\mathrm{A}}$ reaches $105^{\circ} \mathrm{C}$ in just $93^{\prime}$, roughly $20^{\prime}$ earlier that plain resin. Since it was hypothesized, as discussed in the previous paragraph, that the GO effect on the chain mobility could be ascribed to the presence of hydrophilic moieties on the nanosheets surfaces covalently interacting with the epoxy resin components, the observed behavior can be now interpreted on the basis of a faster availability of these moieties for reaction, when nanosheets are delivered within the epoxy component, instead of being solvated by the amine hardener molecules. This behavior would in principle lead to some additional overheating with respect to $\mathrm{R}+\mathrm{H}$, that however is not observed, and the reason can be ascribed to the presence of GO nanosheets. Indeed resin's thermal conductivity was set at $0.2 \mathrm{~W} / \mathrm{mK}$ for the simulation, while GO was reported to be around roughly $10-40 \mathrm{~W} / \mathrm{mK}$ [39], and, although well below the percolation threshold that guarantees full thermal conduction to the isolating resin $(0.05 \%$ in the present work, vs $2 \%$ of Wang et al. [19]), it might as well contribute to some local heat dissipation and propagation. GO-based nanocomposites follow smoothly $\mathrm{R}+\mathrm{H}$ behavior in the initial steps, showing a significant inertia in following the curing cycle. Conversely, both $\mathrm{G}$ containing formulations display a smaller delay during the early minutes of the first heating process, before the cross-linking starts to take place (See Figure 6b, up to 50'). Then, when the exothermic chain reaction begins, the presence of $\mathrm{G}$ among the resin' components leads to a definitely lower overheat phenomenon, almost absent in the case of G-b (maximum $T_{A}=92^{\circ} \mathrm{C}$ and $82^{\circ} \mathrm{C}$ for $\mathrm{R}+\mathrm{H}-\mathrm{G} 500$ and R-cG500+H respectively, Figure 4).

Worth noting is also that in the case of $G$ containing nanocomposites, small deviations from the temperature profile are observed in the further heating steps of the process, that are not detected in $\mathrm{R}+\mathrm{H}$ nor in the GO containing formulations, that are interpreted as lesser delayed overheat phenomena (Figure 6a). The overall behavior of G-d and G-b, i.e. smaller thermal inertia, observed in the early step of the process, together with a less intense and more widespread overheating, accounts for a nanofiller that is not able to covalently interact with the neighbouring reactive moieties of the resin's components, thus not adding some heat input to the system, but might contribute to improve the heat conduction of the mass though still below its percolation threshold. The local heat conduction hypothesis has been already used to explain the GO effect on the simulated temperature profiles. In the case of GO however, the thermal conductivity is far smaller than the $G$ one (roughly $5 \%$ of $G$ thermal conductivity [19]) and the heat distribution effect is far less efficient than in the G-based nanocomposites. The high thermal conductivity of the single graphene sheets can contribute significantly to the overall heat transport, though the mechanism is still not fully clear [19]. Besides, in the present case, graphene acts as a hindering agent, slowing down the motion of the resin components and acting like a barrier that slows down the reaction rate of neighbouring moieties, helping prevent heat accumulation. 

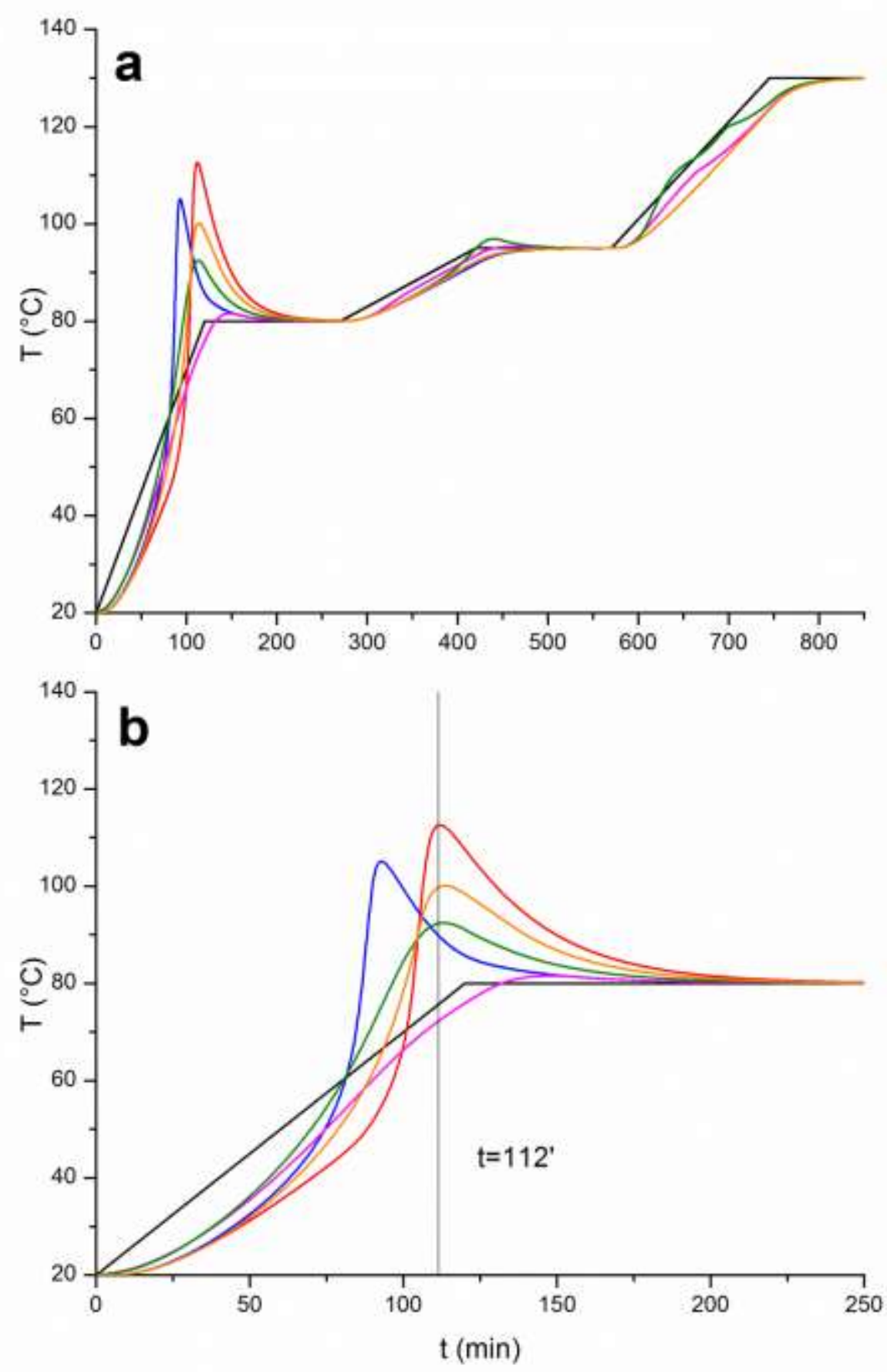

Figure 6 Simulated temperature profile of the curing process of a 50mm thick CFRP beam evaluated at $25 \mathrm{~mm}$ from the surface: a) overall curing process; b) magnification of the early stages of the curing for: Ref (--); G-b (--);G-d (--); GO-b (--); GO-d (--) . In black the imposed curing temperature profile, applied at the outer surface of the beam.

In summary, the obtained experimental results and the simulations indicate a significantly different 
behaviour of GO and graphene. While the former provides additional reactive sites for the curing reaction, thus increasing overheating, the latter does not interact chemically with the matrix, but acts as a thermally conductive additive, enhancing heath distribution and dispersion.

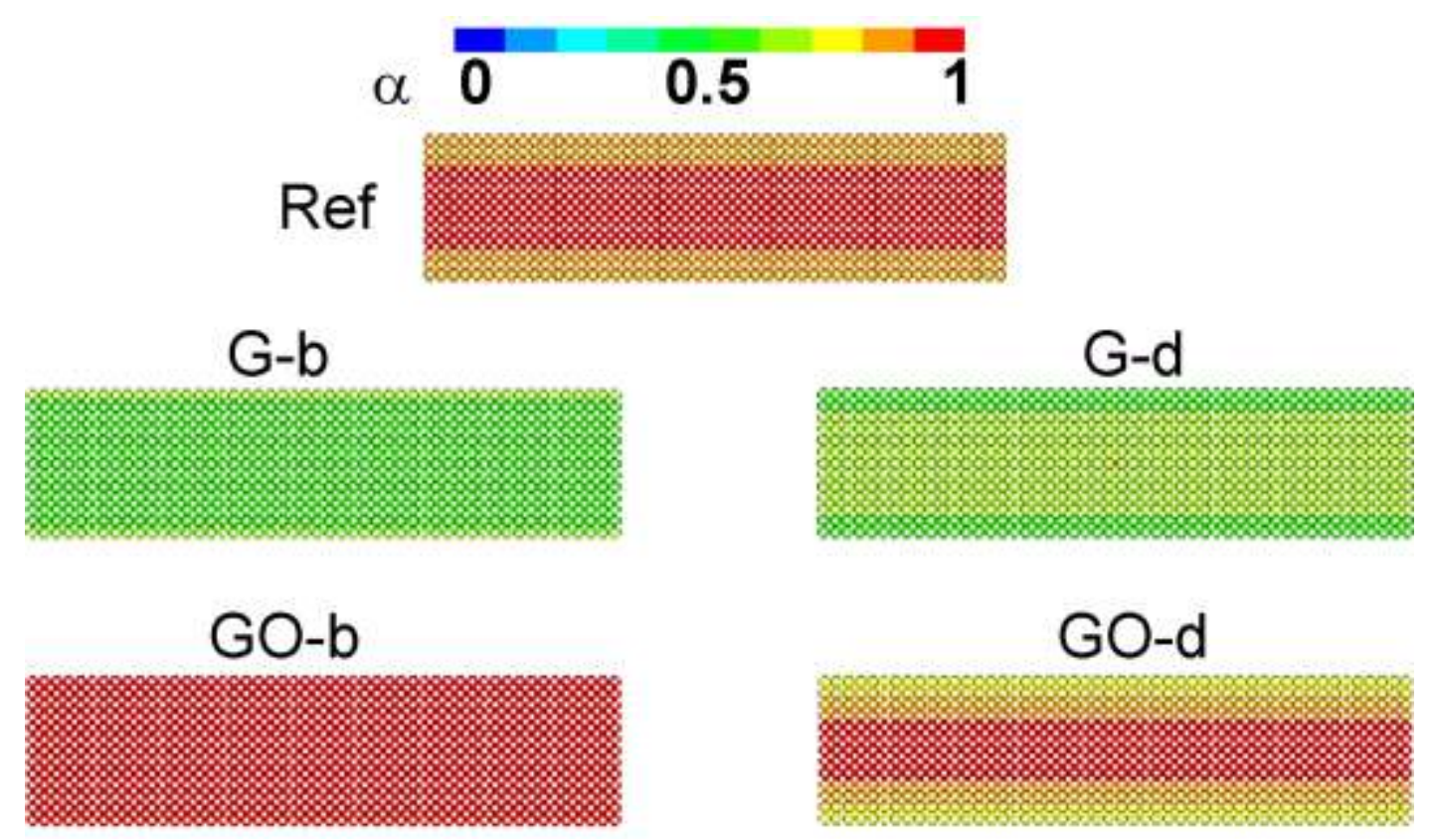

Figure 7 Simulated instant curing degree (a) representation of a 50mm thick CFRP beam, displayed as a portion of the infinite beam section, at $\mathrm{t}=112$ 'when different resins are used as the polymer matrix.

As previously discussed in the kinetics parameters evaluation paragraph, the actual calculated kinetics parameters are valid in the early phases of the cross-linking process, hence not allowing their application at a high curing degree; the simulated instant cure degree (a) might however help displaying how the curing of the part develops, at least in the early stage. Figure 7 shows the simulated curing profile in the beam longitudinal section at $\mathrm{t}=112$, i.e. when the plain $\mathrm{R}+\mathrm{H}$ resin reaches the highest temperature. It is possible to observe that the graphic representation of the beam section shows a gradient profile with a degree of curing that is higher in the center, owing to the heat accumulation that pushes the reaction at the core. This representation of the reaction progress helps understanding the importance in controlling the temperature profile during the curing of the thick CFRC. While, as expected, GO accelerates the curing leading to a very fast reaction proceeding, $G$ leads to a slow process that has no requirement for heat dissipation. Temperature unevenness is in turn correlated with an inhomogeneous degree of cure, responsible for the internal tensions developed during this stage that could end up in deformations due to local differences [5]. Hence the overheating reduction effect would positively contribute to reducing the inhomogeneity, with a better controlled process that can also lower the time required for a single 
industrial production cycle, since no significant time for overheat dispersion is required, thus helping increasing the production rate.

The results obtained indicate that two related 2D materials ( $\mathrm{G}$ and $\mathrm{GO}$ ) have different but complementary effects on curing speed and heath transport. This could allow (by using a mixture of the two) to fine-tune the reaction speed, providing accurate control of the curing process for thick CFRC, much better than the actual state of the art, as schematically depicted in Figure 8.

\section{BLANK RESIN}

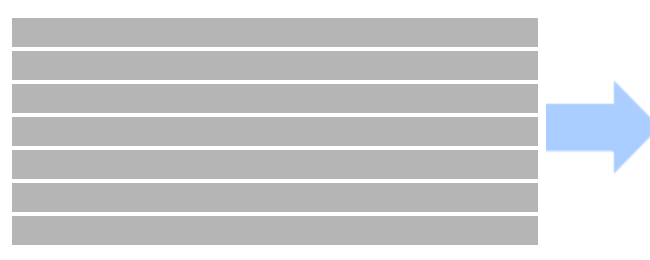

LAYERS WITH VARIABLE

G AND GO LOADING

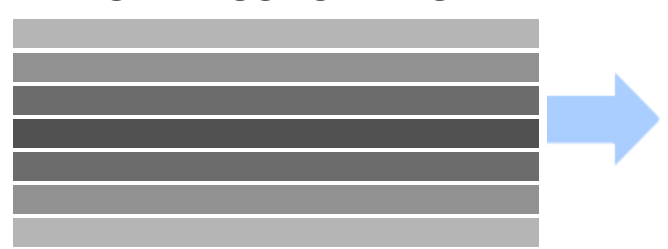

Q overheating of INNER LAYERS

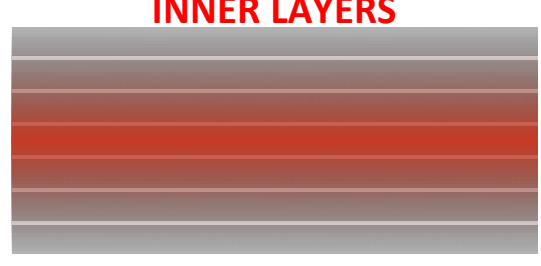

UNIFORM TEMPERATURE

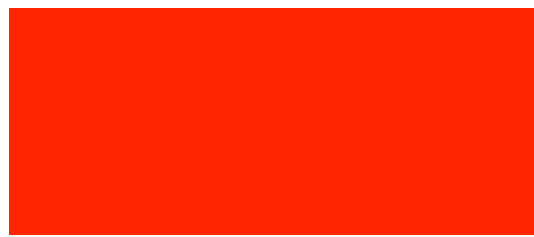

Figure 8. Schematic representation of the use of differently G and GO layers to promote heat control during thick composite curing.

We can also envisage the application of this finding to engineer thick CFRC composed of layers featuring different loading of GO or G; the inner layers could contain more G and GO than the outer ones, yielding thus a faster curing of the inner part of the composite AND a better removal of excessive heath as compared to the outer layers.

\section{Conclusion}

Modification of a commercial epoxy resin formulation with graphenic derivatives was efficiently carried out, investigating different dispersion methods for the nanofillers in the resin precursors. The different formulations show significant and promising improvements of the thermo-mechanical properties that depend both on the GRM applied and on the dispersion method.

While the GO provides additional reactive sites for the curing reaction, thus increasing overheating, 
graphene does not interact chemically with the matrix, but acts as a thermally conductive additive, enhancing heath distribution and dispersion.

All the resins but those with GO dispersed directly in the hardener display a drop in their performance passing from 250ppm GRM load to 500ppm. When GO is delivered via the hardener, no drop is observed, possibly owing to the good interaction between the nanofillers and the dispersion medium.

The evaluation of the kinetics parameters of the modified resins during the curing process allowed the simulation of a possible industrial application of these resins in the production of a thick carbon fiber reinforced beam. The simulation highlighted some interesting effects of graphene that helps to smooth, or even completely prevent, the overheating phenomena typical of thick composites production, that are well renown to induce significant thermal stresses negatively affecting the final object performances.

The possibility to have two related 2D materials ( $\mathrm{G}$ and GO) having different, complementary effects on curing speed and heath transport could allow (by using a mixture of the two) to fine-tune the reaction progress allowing control of curing of thick CFRC much better than the actual one.

\section{Acknowledgements}

This work is part of "Pro.Ma.Tec. (Processi e Materiali Innovativi Tecnologicamente Avanzati per la Meccanica)" project, that is funded by Regione Emilia Romagna within the funding program "Dai distretti produttivi ai distretti tecnologici" DGR n. 1631/2009. 
[1] Dmitriev O, Mischenko S. Optimization of Curing Cycles for Thick-wall Products of the Polymeric Composite Materials. In: Attafs B, editor. Advances in Composite Materials - Ecodesign and Analysis. InTech; 2011. p. 141-60.

[2] Giorgini L, Mazzocchetti L, Benelli T, Minak G, Poodts E, Dolcini E 2013 Polym Compos 34 15061514.

[3] Poodts E, Minak G, Mazzocchetti L, Giorgini L 2014 Composites Part B 56 673-680.

[4] Secord TW, Mantell SC, Stelson KA 2011 J Manuf Sci Eng 133011005.

[5] Antonucci V, Giordano M, Hsiao KT, Advani SG 2002 Int J Heat Mass Transfer 45 1675-1684.

[6] Radford DW 1993 J Compos Tech Res 15 290-296.

[7] Samori P, Kinloch IA, Feng X, Palermo V 2015 2D Mater 2030205.

[8] Xia W, Xue H, Wang J, Wang T, Song L, Guo H, et al. 2016 Carbon 101 315-323.

[9] Nakamura S, Doi Y, Scandola M 1992 Macromolecules 25 4237-4241.

[10] Eksik O, Bartolucci SF, Gupta T, Fard H, Borca-Tasciuc T, Koratkar N 2016 Carbon 101 239-244.

[11] Ferrari AC, Bonaccorso F, Fal'ko V, Novoselov KS, Roche S, Boggild P, et al. 2015 Nanoscale 7 4598-4810.

[12] Compton OC, Nguyen SBT 2010 Small 6 711-723.

[13] Sisti L, Belcari J, Mazzocchetti L, Totaro G, Vannini M, Giorgini L, et al. 2016 Polymer Testing 50 283-291.

[14] Schopp S, Thomann R, Ratzsch KF, Kerling S, Altstädt V, Mülhaupt R 2014 Macromol Mater Eng 299 319-329.

[15] Tschoppe K, Beckert F, Beckert M, Mülhaupt R 2015 Macromol Mater Eng 300 140-152.

[16] Young RJ, Liu M 2016 J Mater Sci 51 3861-3867.

[17] Shtein M, Nadiv R, Buzaglo M, Kahil K, Regev O 2015 Chem Mater 27 2100-2106.

[18] Song SH, Park KH, Kim BH, Choi YW, Jun GH, Lee DJ, et al. 2013 Adv Mater 25 732-737.

[19] Wang B, Hao J, Li H 2013 Dalton Trans 42 5866-5873.

[20] Wan YJ, Tang LC, Gong LX, Yan D, Li YB, Wu LB, et al. 2014 Carbon 69 467-480.

[21] Demaría C, Ruiz E, Trochu F 2007 Polym Compos 28 812-827. 
[22] Griffis CA, Masumura RA, Chang CI 1981 J Compos Mater 15 427-442.

[23] Johnston A, Vaziri R, Poursartip A 2001 J Compos Mater 35 1435-1469.

[24] Tian T, Cole KD 2012 Int J Heat Mass Transfer 55 6530-6537.

[25] Villière M, Lecointe D, Sobotka V, Boyard N, Delaunay D 2013 Composites Part A 46 60-68. [26]

Paredes JI, Villar-Rodil S, Marti|ïnez-Alonso A, Tascołün JMD 2008 Langmuir 24 10560-10564. [27]

Hernandez Y, Lotya M, Rickard D, Bergin SD, Coleman JN 2010 Langmuir 26 3208-3213.

[28] Liscio A, Veronese GP, Treossi E, Suriano F, Rossella F, Bellani V, et al. 2011 J Mater Chem 21 2924-2931.

[29] Scandola M, Pizzoli M. Plasticizers (Polymer-plasticizer Interactions). In: Salamone JC, editor. Polymeric Materials Encyclopedia. CRC Press; 1996. p. 5301-8.

[30] McCrum NG, Read BE, Williams G. Anelastic and dielectric effects in polymeric solids. Dover Publications; 1991.

[31] Chandrasekaran S, Sato N, Tölle F, Mülhaupt R, Fiedler B, Schulte K 2014 Compos Sci Technol 97 90-99.

[32] Sourour S, Kamal MR 1976 Thermochim Acta 14 41-59.

[33] Kamal MR, Sourour S 1973 Polym Eng Sci 13 59-64.

[34] Opalicki M, Kenny JM, Nicolais L 1996 J Appl Polym Sci 61 1025-1037.

[35] Vyazovkin S, Burnham AK, Criado JM, Pérez-Maqueda LA, Popescu C, Sbirrazzuoli N 2011 Thermochim Acta 520 1-19.

[36] Kenny JM, Opalicki M 1993 Makromol Chem -M Symp 68 41-56.

[37] Martin-Gallego M, Bernal MM, Hernandez M, Verdejo R, Lopez-Manchado MA 2013 Eur Polym J 49 1347-1353.

[38] Sain PK, Goyal RK, Prasad YVSS, Jyoti, Sharma KB, Bhargava AK 2015 J Appl Polym Sci 132 42443.

[39] Shen X, Lin X, Jia J, Wang Z, Li Z, Kim JK 2014 Carbon 80 235-245. 